\title{
Environmental factors in aetiology of chronic gastric ulcer: a case control study of exposure variables before the first symptoms
}

\author{
J H MCINTOSH, KAREN BYTH, AND D W PIPER \\ From the Department of Medicine, Royal North Shore Hospital, Sydney, New South Wales, Australia
}

SUMmaRY The aim of the present study was to determine whether there is indication that either smoking, alcohol ingestion, or ingestion of analgesic or non-salicylate non-steroidal antiinflammatory drugs plays any role in the development of chronic gastric ulcer disease. A group of 104 patients with gastric ulcer was compared with an age, sex and social grade matched community control population as regards exposure to the above factors during three time periods - the lifetime, five year and one year periods before the initial onset of the patients' ulcer symptoms. In all three study periods a statistically significant risk of gastric ulcer was found to be associated with smoking, and the daily use of aspirin, indomethacin and of other non-salicylate non-steroidal anti-inflammatory drugs as a group, but not with alcohol or daily use of paracetamol. As exposure to the environmental factors preceded the initial onset of ulcer symptoms, causal relationships are suggested. Assuming the associations are causal, it can be calculated that possibly up to $80 \%$ of gastric ulcer disease is attributable to smoking and the daily ingestion of analgesic and anti-inflammatory drugs.

Gastric ulcer, though unaccompanied by any gastric secretory abnormality, ${ }^{12}$ has been shown to be markedly associated with smoking, ${ }^{3-5}$ and daily analgesic ingestion..$^{5-8}$ Although shown to be associated with a prevalent ulcer, as yet it has not been shown that exposure to these factors precedes the development of ulcer, as would be required if a causal relationship were to be postulated. ${ }^{9-13}$ The aim of the present study was to define the association of gastric ulcer with smoking, alcohol consumption and the ingestion of analgesic drugs (aspirin and/or paracetamol) and non-salicylate nonsteroidal anti-inflammatory drugs (NSNSAID) before the initial onset of ulcer symptoms.

\section{Methods}

PATIENTS

One hundred and four patients (41 men and 63 women) in whom gastric ulcer was diagnosed at Royal North Shore Hospital and who were Sydney residents were included in the study. Entry criteria were an endoscopically and histologically proven

Address for correspondence: Professor D W Piper, Department of Medicine. Royal North Shore Hospital, St Leonards, NSW 2065, Australia.

Received for publication 9 August 1984 chronic gastric ulcer located between the cardiooesophageal junction and the pylorus, and initial onset of ulcer symptoms no earlier than five years before interview. Gastric ulcer site was not differentiated as the exposure factors under study do not appear to influence site. ${ }^{14}$ Length of symptom history was limited to five years in the attempt to reduce recall bias. Patients with a history of duodenal ulcer, hiatus hernia, oesophageal reflux, etc, were excluded to ensure as far as possible that symptom experience pertained only to gastric ulcer. Apart from necessity to fulfil the above criteria, patients were unselected.

Of all patients whom it was desired to contact as regards selection for the study, $98 \%$ possessed a private telephone. All interviews took place during 1980 and 1981.

COMMUNITY CONTROL SELECTION

Controls were randomly selected from the Sydney electoral rolls. (In Australia, registration for voting is compulsory for all persons 18 years old and over.) These persons were telephoned, informed of the study and asked if they were willing to participate. Each patient was matched with two controls for age ( \pm 10 years), sex and social grade of address using 
Congalton's status ratings of Sydney suburbs. ${ }^{15}$ Persons were ineligible as controls if a history of peptic ulcer were known or probable; therefore community persons were questioned as regards any past or present experience of dyspepsia (defined as persistent or recurring abdominal pain or discomfort) and any radiological or endoscopic investigations. Eighteen per cent of persons approached were found to have a history of ulcer or dyspepsia.

Exclusion clauses which applied for the selection of both patients and controls were: (1) difficulty in understanding English (four patients, five community persons); (2) mental disability (three patients, two community persons); (3) other prevailing severe physical illness (two patients, two community persons).

Ninety five per cent of patients and $95 \%$ of potential control subjects who were approached and were eligible for the study agreed to participate.

\section{DATA COLLECTION}

Patients and controls were interviewed by telephone, a method well validated for data collection, ${ }^{16-19}$ and were asked, by means of a structured questionnaire, their patterns of smoking, drinking alcohol and ingestion of aspirin and/or paracetamolcontaining drugs and non-salicylate non-steroidal anti-inflammatory drugs (indomethacin, naproxen, ibuprofen, phenylbutazone, etc) during three time periods: (1) the lifetime period until onset of initial ulcer symptoms; (2) the five years before onset of initial ulcer symptoms; (3) the one year before onset of initial ulcer symptoms.

The time periods of study for each control corresponded to those of his/her matched patient.

\section{STATISTICAL ANALYSIS}

The data were analysed using logistic regression analysis for matched sets. ${ }^{20}$ This approach assumes that the logarithm of the odds ratio is some linear combination of the exposure factors; that is, that the effects of the factors are multiplicatively cumulative in the absence of any significant interactions.

The 'best fitting model' is that logistic regression model which can account for the largest amount of the inherent variability in the data; thus the best fitting model could be said to give the most adequate 'explanation' of the data. After examination of the effect of each factor irrespective of the other factors under study, logistic regression analysis permits the inter-relationships between the effects of factors to be examined more closely should these prove to be of importance. The best fitting model is found by adding terms step wise to the regression equation and retaining only those terms which significantly improve the fit of the model to the data. The odds ratios and associated confidence intervals are derived from the fitted regression coefficients and their standard errors in the best fitting model.

Logistic regression analysis for matched sets requires consideration of the joint exposure of the case and controls in each set. It is not possible to simply use the total numbers of cases and controls exposed or unexposed to derive the correct odds ratios,${ }^{20}$ therefore such frequencies can only provide rough estimates of the true odds ratios. The statistical packages SPSS (Release 8) and GLIM (Version 3) were used to perform the analyses.

The following exposure variables were required in the best fitting models for each time period:

Smoking: (1) smoker $-\geqslant$ one cigarette daily for at least six consecutive months; (0) non-smoker otherwise.

Alcohol: (1) heavy drinker - >60 g alcohol daily for at least six consecutive months; $(0)$ non-drinker or light/moderate drinker - otherwise.

Analgesic drugs (this group includes aspirin and paracetamol either alone or in combination): (1) Daily user $-\geqslant$ seven tablets (powders or capsules) weekly for at least two consecutive months; (0) non-daily user - otherwise.

Non-steroidal, non-salicylate, anti-inflammatory drugs (NSNSAID): (1) daily user $-\geqslant$ seven tablets or capsules weekly for at least four consecutive weeks; (0) non-daily user - otherwise.

The best fitting model for the lifetime period required further categorisation of the users of analgesic drugs as follows: (0) non-daily user $-<$ one tablet daily, or one to five tablets daily for less than two consecutive months; (1) light/moderate daily user - one to five tablets daily for at least two consecutive months and $>$ five tablets daily for less than two consecutive months; (2) heavy daily user $>$ five tablets daily for at least two consecutive months.

The best fitting models for the lifetime and five years prior periods were the simple main effects only models with $\log$ (odds ratio) $=\alpha$ (smoking) $+\beta$ (analgesic drugs) $+\gamma$ (NSNSAID). For the one year prior period, the best fitting model required the addition of a $\delta$ (smoking $\times$ analgesic drugs) interaction term to the above, $\alpha, \beta, \gamma$, and $\delta$ being the regression coefficients to be estimated from the data in each time period.

The following variables, designed to represent the total amount of each exposure factor consumed, were also of use in modelling the lifetime period: 'pack year' $=$ consumption of 20 cigarettes per day for one year; 'nip year' = consumption of one alcoholic drink (10 g alcohol) per day for one year; 'tablet year' = consumption of one tablet or powder per day for one year. 
Thus, a subject may score a fractional number for 'pack years' - for example, $0 \cdot 5$, if that subject smoked 10 cigarettes per day for just one year of the lifetime period before initial onset of symptoms.

The term, 'sole factor', was used to describe exposure to only one factor during a study period. 'Multiple factors' was used to describe exposure to two or more factors either simultaneously, or else singly at different times during a study period.

The population attributable risk was estimated using the method described by Whittemore. ${ }^{21}$ This statistic, also called the aetiologic fraction, ${ }^{22}$ refers to the percentage of the total prevalence of disease amongst a population, which can be attributed to exposure to these factors, and therefore it indicates the proportion of disease that would not have occurred had such exposure been absent. The population attributable risk is calculated as a percentage and derives from the numbers in the patient and control populations exposed and unexposed to the risk factors.

\section{Results}

Examination of the effect of each exposure variable regardless of the other variables, revealed that in all three time periods, smoking and daily usage of analgesic drugs and NSNSAID's were indicated as risk factors for gastric ulcer (all $p$ values $<0.01$ ), while alcohol usage was not (all $p$ values $>0.05$ ). The odds ratios and $95 \%$ confidence intervals showing the strength of relationships between gastric ulcer risk and these factors are presented in Table 1.

Further analysis of the data exploring the interrelationships between the significant exposure factors produced the odds ratios and $95 \%$ confidence intervals shown in Tables 2, 3, and 4. Because alcohol use was not significantly associated with gastric ulcer, these odds ratios apply for all levels of drinking. To summarise these results: (a) in all three time periods, risk of gastric ulcer was associated at the $1 \%$ level of significance with smoking, daily use of analgesic drugs and daily use of NSNSAID's when present as sole or as multiple factors; (b) of the two way interactions of the exposure variables, only smoking $x$ daily analgesic drug use during the year before initial onset of symptoms was significant at the $5 \%$ level. This was a negative interaction; (c) there were no significant interactions between the matching variables (age, sex, social grade) and the exposure variables in any time period; (d) for the lifetime period, the odds ratios for daily analgesic drug ingestion exhibit the dose response relationship between risk of gastric ulcer and ingestion of analgesic drugs, the odds being markedly increased when one to five tablets daily was increased to greater than five tablets daily (Table 4). For the one year and five year time periods, no dose response effects significant at the $5 \%$ level could be detected for any exposure factor.

When the total amounts (of exposure factors) consumed during the lifetime period before the initial onset of symptoms were used as regression variables, dose-response effects significant at the $1 \%$ level were observed for all exposure factors except alcohol, for which no dose response effect significant even at the $5 \%$ level was observed. Of the two way interactions between the exposure variables (as regards total amounts), only smoking $x$ daily NSNSAID use was significant at the 5\% level. This interaction was negative. There was no interaction significant at the $5 \%$ level between the total amounts of exposure variables and the matching variables. When data concerning the total amounts of NSNSAID were analysed, 10 case control sets were excluded because one member from each of the 10 sets (seven patients and three controls in all) who were daily users of NSNSAID could not remember how many tablets were taken daily during the lifetime period. There were no other missing data throughout the study.

Tables 1 and 5 show that proportionately more patients than controls consumed $>60 \mathrm{~g}$ alcohol daily. The odds ratios associated with this level of consumption, however, both unadjusted (Table 1) and adjusted for smoking, analgesics and NSNSAID's (Table 5), did not differ significantly from unity.

Table 6 presents the frequency distribution of the drugs involved in daily use of analgesics and NSNSAID's during the three time periods; smokers are indicated in parentheses.

Table 7 gives the odds ratios and $95 \%$ confidence intervals which display the strengths of the relationships between the drugs and risk of gastric ulcer. The $\chi^{2}$ heterogeneity test shows the significance of difference between the odds ratios within the analgesic and NSNSAID categories. It can be seen that in all three time periods, risk of gastric ulcer was associated with daily use of aspirin, of indomethacin, and of the other NSNSAID's as a group, but not with paracetamol. In 30 of the 104 patients, initial ulcer symptoms included bleeding. The remaining 74 patients had presented with dyspepsia or vomiting and no patients had presented with perforation. Of the 30 patients who bled, 17 had taken aspirin and/or NSNSAID's daily during the year before the onset of symptoms. Of these 17, nine had taken aspirin (no NSNSAID's), five had taken NSNSAID's (no aspirin) and three had taken both aspirin and NSNSAID's. When these frequen- 
Table 2 OR's and 95\% Cl's for the effect of the significant risk factors when one or more factors were present during the one year period before symptom onset

\begin{tabular}{llcr}
\hline Exposure & $\begin{array}{l}\text { Patients } \\
n=104\end{array}$ & $\begin{array}{l}\text { Controls } \\
n=208\end{array}$ & OR and 95\% CI \\
\hline Nil & $17(16 \%)$ & $150(72 \%)$ & $1 \cdot 0$ \\
Sole factors & & & \\
$\quad$ Smoking & $36(35 \%)$ & $41(20 \%)$ & $16 \cdot 9(3 \cdot 3-14 \cdot 2)$ \\
Daily analgesic drugs* & $14(13 \%)$ & $5(2 \%)$ & $4(5 \cdot 2-51 \cdot 6)$ \\
Daily NSNSAID & $7(7 \%)$ & $7(3 \%)$ & $4 \cdot 7(1 \cdot 3-16 \cdot 6)$ \\
Multiple factors & & & $18 \cdot 2(2 \cdot 1-162)$ \\
Smoking + daily analgesic drugs & $14(13 \%)$ & $4(2 \%)$ & $32 \cdot 1(7 \cdot 4-139)$ \\
Smoking + daily NSNSAID & $6(6 \%)$ & $1(1 \%)$ & $76 \cdot 3(13 \cdot 7-424)$ \\
Daily analgesic drugs + daily NSNSAID & $9(9 \%)$ & 0 & $84 \cdot 7(6 \cdot 8-1060)$ \\
Smoking + daily analgesic drugs + daily NSNSAID & $1(1 \%)$ & 0 & \\
\hline
\end{tabular}

* This effect due to aspirin as in no patients or controls was daily paracetamol alone a sole factor.

Table 3 OR's and 95\% CI's for the effect of the significant risk factors when one or more factors were present during the five year period before symptom onset

\begin{tabular}{|c|c|c|c|}
\hline Exposure & $\begin{array}{l}\text { Patients } \\
n=104\end{array}$ & $\begin{array}{l}\text { Controls } \\
n=208\end{array}$ & OR and $95 \% \mathrm{Cl}$ \\
\hline Nil & $14(13 \%)$ & $139(67 \%)$ & $1 \cdot 0$ \\
\hline $\begin{array}{l}\text { Sole factors } \\
\text { Smoking } \\
\text { Daily analgesic drugs* } \\
\text { Daily NSNSAID }\end{array}$ & $\begin{array}{l}35(34 \%) \\
12(11 \%) \\
10(10 \%)\end{array}$ & $\begin{array}{c}46(22 \%) \\
6(3 \%) \\
9(4 \%)\end{array}$ & $\begin{array}{l}5 \cdot 2(2 \cdot 7-9 \cdot 6) \\
6 \cdot 1(2 \cdot 8-13 \cdot 4) \\
4 \cdot 5(1 \cdot 7-122)\end{array}$ \\
\hline $\begin{array}{l}\text { Multiple factors } \\
\text { Smoking + daily analgesic drugs } \\
\text { Smoking + daily NSNSAID } \\
\text { Daily analgesic drugs + daily NSNSAID } \\
\text { Smoking + daily analgesic drugs + daily NSNSAID }\end{array}$ & $\begin{array}{c}16(15 \%) \\
5(5 \%) \\
10(10 \%) \\
2(2 \%)\end{array}$ & $\begin{array}{l}5(2 \%) \\
1(1 \%) \\
2(1 \%) \\
0\end{array}$ & $\begin{array}{l}30 \cdot 9(11 \cdot 2-85 \cdot 3) \\
22 \cdot 7(6 \cdot 9-74 \cdot 1) \\
27 \cdot 3(7 \cdot 6-97 \cdot 6) \\
138(13 \cdot 3-575)\end{array}$ \\
\hline
\end{tabular}

* This effect predominantly due to aspirin as in no patients and only two controls was daily paracetamol alone a sole factor.

Table 4 OR's and 95\% CI's for the effect of the significant risk factors when one or more factors were present during the lifetime period before symptom onset

\begin{tabular}{|c|c|c|c|}
\hline Exposure & $\begin{array}{l}\text { Patients } \\
n=104\end{array}$ & $\begin{array}{l}\text { Controls } \\
n=208\end{array}$ & $O R$ and $95 \% \mathrm{CI}$ \\
\hline Nil & $9(9 \%)$ & $86(40 \%)$ & 1.0 \\
\hline $\begin{array}{l}\text { Sole factors } \\
\text { Smoking } \\
\text { Analgesic drugs* (1-5 tablets daily) } \\
\text { Analgesic drugs* (>5 tablets daily) } \\
\text { Daily NSNSAID }\end{array}$ & $\begin{array}{c}37(35 \%) \\
8(8 \%) \\
2(2 \%) \\
5(5 \%)\end{array}$ & $\begin{array}{c}85(40 \%) \\
12(6 \%) \\
1(1 \%) \\
7(3 \%)\end{array}$ & $\begin{array}{c}2 \cdot 3(1 \cdot 3-4 \cdot 2) \\
3 \cdot 6(1 \cdot 8-7 \cdot 2) \\
17 \cdot 5(2 \cdot 3-136) \\
6 \cdot 4(2 \cdot 3-17 \cdot 6)\end{array}$ \\
\hline $\begin{array}{l}\text { Multiple factors } \\
\text { Smoking + analgesic drugs ( } 1-5 \text { tablets daily) } \\
\text { Smoking + analgesic drugs ( }>5 \text { tablets daily) } \\
\text { Smoking + daily NSNSAID } \\
\text { Analgesic drugs (1-5 tablets daily) + daily NSNSAID } \\
\text { Analgesic drugs ( }>5 \text { tablets daily) + daily NSNSAID } \\
\text { Smoking + analgesic drugs (1-5 tablets daily) + daily NSNSAID } \\
\text { Smoking + analgesic drugs ( }>5 \text { tablets daily) + daily NSNSAID }\end{array}$ & $\begin{array}{c}13(12 \%) \\
4(4 \%) \\
11(10 \%) \\
3(3 \%) \\
5(5 \%) \\
5(5 \%) \\
2(2 \%)\end{array}$ & $\begin{array}{l}10(5 \%) \\
1(1 \%) \\
4(2 \%) \\
1(1 \%) \\
0 \\
1(1 \%) \\
0\end{array}$ & $\begin{array}{c}8 \cdot 5(3 \cdot 4-20 \cdot 9) \\
40 \cdot 9(10 \cdot 5-345) \\
14 \cdot 9(4 \cdot 6-48 \cdot 1) \\
23 \cdot 2(6 \cdot 8-78 \cdot 8) \\
112 \cdot 0(11 \cdot 4-1100) \\
54 \cdot 1(13 \cdot 9-211) \\
261 \cdot 0(24 \cdot 7-2760)\end{array}$ \\
\hline
\end{tabular}

\footnotetext{
* These effects predominantly due to aspirin as in no patients and only three controls was daily paracetamol a sole factor.
} 
Table 5 Frequency distribution amongst patients and controls of different levels of alcohol consumption during the three time periods

\begin{tabular}{|c|c|c|c|c|c|c|c|c|c|}
\hline \multirow[b]{2}{*}{$\begin{array}{l}\text { Alcohol } \\
\text { exposure }\end{array}$} & \multicolumn{3}{|c|}{ One year before } & \multicolumn{3}{|c|}{ Five years before } & \multicolumn{3}{|c|}{ Lifetime before } \\
\hline & $\begin{array}{l}\text { Patients } \\
n=104\end{array}$ & $\begin{array}{l}\text { Controls } \\
n=208\end{array}$ & $O R^{*}$ & $\begin{array}{l}\text { Patients } \\
n=104\end{array}$ & $\begin{array}{l}\text { Controls } \\
n=208\end{array}$ & $O R^{*}$ & $\begin{array}{l}\text { Patients } \\
n=104\end{array}$ & $\begin{array}{l}\text { Controls } \\
n=208\end{array}$ & $O R^{*}$ \\
\hline Nil & 43 & 64 & $1 \cdot 0$ & 36 & 62 & $1 \cdot 0$ & 34 & 59 & 1.0 \\
\hline$>0 \mathrm{~g} \leqslant 20 \mathrm{~g}$ daily & 42 & 114 & $\begin{array}{l}0.6 \\
0 \cdot 3-1 \cdot 1\end{array}$ & 46 & 110 & $\begin{array}{l}0.8 \\
0.4-1.5\end{array}$ & 46 & 110 & $\begin{array}{l}0.9 \\
0.5-1.6\end{array}$ \\
\hline$>20 \mathrm{~g} \leqslant 60 \mathrm{~g}$ daily & 12 & 24 & $\begin{array}{l}0 \cdot 6 \\
0 \cdot 2-1 \cdot 5\end{array}$ & 13 & 30 & $\begin{array}{l}0.7 \\
0 \cdot 3-1 \cdot 7\end{array}$ & 11 & 29 & $\begin{array}{l}1 \cdot 3 \\
0 \cdot 5-3 \cdot 2\end{array}$ \\
\hline$>60$ g daily & 7 & 6 & $\begin{array}{l}1 \cdot 4 \\
0 \cdot 4-5 \cdot 1\end{array}$ & 9 & 6 & $\begin{array}{l}1 \cdot 8 \\
0.5-6 \cdot 6\end{array}$ & 13 & 10 & $\begin{array}{l}1 \cdot 8 \\
0 \cdot 6-6 \cdot 4\end{array}$ \\
\hline
\end{tabular}

* OR's adjusted for smoking, daily analgesic drugs and daily NSNSAID's.

cies are compared with those on Table 6 which shows the total numbers of daily takers of these drugs, it can be seen that only a minority $(27 \%)$ of the daily takers of aspirin and/or NSNSAID during the year before symptom onset went on to experience gastric haemorrhage.

The mean length of time between symptom onset and interview was 2.1 years with a range of two months to five years. For $34 \%$ of patients the length of this time period was one year and under, for $57 \%$ two years and under, for $76 \%$ three years and under and for $92 \%$ four years and under.

The mean age of patients at symptom onset was 58 years with a range of 23 to 83 years. Twenty $(19 \%)$ patients and $42(20 \%)$ controls were under age 50 years, $32(31 \%)$ patients and $56(27 \%)$ controls were aged 50-59 years, $25(24 \%)$ patients and $62(30 \%)$ controls were aged 60 to 69 years and
$27(26 \%)$ patients and $48(23 \%)$ controls were aged 70 years or more.

As regards social grade distribution, 15 patients lived in A grade suburbs, 78 in B grade, 11 in C grade, and none in D grade.

POPULATION ATTRIBUTABLE RISK

The estimates of gastric ulcer risk attributable to exposure to smoking, analgesic drugs and NSNSAID's are shown in Table 8. As any exposure to these risk factors a patient or control may have had was recorded in the lifetime period, data for this period were considered the most appropriate for population attributable risk estimation. The population attributable risk's for each of the three risk factors - smoking, analgesic drugs and NSNSAID's - were adjusted to control the effect of the other two risk factors. These population attributable risk

Table 6 Distribution of drug type amongst patient and control daily users of analgesic and NSNSAID during the three time periods

\begin{tabular}{|c|c|c|c|c|c|c|}
\hline \multirow[b]{2}{*}{ Exposure category } & \multicolumn{2}{|c|}{ One year before } & \multicolumn{2}{|c|}{ Five years before } & \multicolumn{2}{|c|}{ Lifetime before } \\
\hline & $\begin{array}{l}\text { Patient } \\
n=104\end{array}$ & $\begin{array}{l}\text { Control } \\
n=208\end{array}$ & $\begin{array}{l}\text { Patient } \\
n=104\end{array}$ & $\begin{array}{l}\text { Control } \\
n=208\end{array}$ & $\begin{array}{l}\text { Patient } \\
n=104\end{array}$ & $\begin{array}{l}\text { Control } \\
n=208\end{array}$ \\
\hline Nil & $53(36)$ & $191(41)$ & $49(35)$ & $185(46)$ & $46(37)$ & $171(85)$ \\
\hline Aspirin (asp) only & $18(8)$ & $7(2)$ & $17(9)$ & $6(2)$ & $16(8)$ & $11(5)$ \\
\hline Paracetamol (para) only & $2(2)$ & $2(2)$ & $2(2)$ & $5(3)$ & $1(1)$ & $7(4)$ \\
\hline Asp + para only & $8(4)$ & $0(0)$ & $9(5)$ & $0(0)$ & $10(8)$ & $6(2)$ \\
\hline Indomethacin only & $9(3)$ & $3(1)$ & $9(3)$ & $4(1)$ & $10(7)$ & $6(2)$ \\
\hline Other NSNSAID & $4(3)$ & $4(0)$ & $5(2)$ & $4(0)$ & $6(4)$ & $3(1)$ \\
\hline Asp + indomethacin & $2(0)$ & $0(0)$ & $3(1)$ & $1(0)$ & $3(1)$ & $1(1)$ \\
\hline Para + indomethacin & $0(0)$ & $0(0)$ & $1(0)$ & $0(0)$ & $1(1)$ & $0(0)$ \\
\hline Asp + para + indomethacin & $1(0)$ & $0(0)$ & $1(0)$ & $0(0)$ & $2(1)$ & $0(0)$ \\
\hline Asp + other NSNSAID & $4(1)$ & $0(0)$ & $4(1)$ & $1(0)$ & $4(3)$ & $0(0)$ \\
\hline Para + other NSNSAID & $2(0)$ & $0(0)$ & $2(0)$ & $0(0)$ & $1(1)$ & $0(0)$ \\
\hline Asp + para + other NSNSAID & $1(0)$ & $0(0)$ & $1(0)$ & $0(0)$ & $3(0)$ & $1(0)$ \\
\hline Indomethacin + other NSNSAID & $0(0)$ & $1(0)$ & $1(0)$ & $2(0)$ & $1(0)$ & $2(1)$ \\
\hline
\end{tabular}

In parentheses, number of smokers in each exposure category. 
Table 8 Estimates of gastric ulcer risk attributable to exposure to smoking, daily analgesic drugs and daily NSNSAID during the lifetime period

\begin{tabular}{|c|c|}
\hline Exposure to & $\begin{array}{l}\text { Attributable risk (PAR) } \\
\text { and } 96 \% \mathrm{CI}\end{array}$ \\
\hline $\begin{array}{l}\text { Smoking } \\
\text { Daily analgesic drugs } \\
\text { Daily NSNSAID } \\
\text { One or more risk factors Men only } \\
\qquad \begin{array}{l}\text { Women only } \\
\text { All }\end{array}\end{array}$ & $\begin{array}{l}40 \cdot 3 \%(28 \cdot 8-51 \cdot 8) \\
32 \cdot 2 \%(20 \cdot 7-43 \cdot 7) \\
25 \cdot 2 \%(20 \cdot 6-29 \cdot 7) \\
52 \%(32 \cdot 4-71 \cdot 6) \\
90 \cdot 2 \%(88 \cdot 4-92 \cdot 0) \\
79 \cdot 1 \%(75 \cdot 2-82 \cdot 9)\end{array}$ \\
\hline
\end{tabular}

estimates are not additive. The estimates of gastric ulcer risk attributable to exposure to any of the risk factors - either alone or in any combination - are also shown in Table 8 both sex-specifically and across the sexes.

The findings indicate that in the group under study, $40 \%$ of gastric ulcer disease is attributable to smoking, $32 \%$ to daily analgesic drugs and $25 \%$ to daily NSNSAID. It is also indicated that these factors as a group account for $52 \%$ of gastric ulcer disease in the men under study and $90 \%$ in the women, and across the sexes they account for $79 \%$ of gastric ulcer disease.

\section{Discussion}

In this study of the exposure variables before the onset of the first symptom in a series of gastric ulcer patients, a strong association of ulcer was found with smoking and daily ingestion of analgesic and antiinflammatory drugs. The crucial question is whether these data and that of others are adequate to postulate a causal relationship, the critiera for which include a correct temporal relationship, strength and consistency of association, the presence of a biological gradient, the biological plausibility of the association and whether the association is supported by coherence. ${ }^{9-13}$ These criteria, in relation to the environmental factors, are summarised in Table 9 and will be briefly commented upon.

\section{SMOKING}

Many studies have shown an association between smoking and prevalent gastric ulcer. ${ }^{3-5}$ High odds ratios as regards smoking have been observed in a previous study ${ }^{5}$ and the finding in the present study of a temporal relationship and a biological gradient (as indicated by the dose response effect over the lifetime period) suggests causality. Smoking, however, has no effect on gastric secretion ${ }^{23}$ and Doll failed to observe a biological gradient. ${ }^{3}$

\section{ALCOHOL}

As found in a previous study of prevalent gastric ulcer, ${ }^{5}$ alcohol use appeared unrelated to gastric ulcer risk. The odds ratios for heavy drinking before the first symptom ( $>60 \mathrm{~g}$ daily) are a little above unity but their lower confidence limits are well below, especially after adjustment for the significant risk factors.

\section{ANALGESIC DRUGS}

The strong association of prevalent gastric ulcer with aspirin and/or paracetamol-containing drugs has been documented in several studies. ${ }^{4-8}$ In the present study, although aspirin was found to be strongly associated with gastric ulcer and paracetamol was not, there were no significant differences between the effects of aspirin and paracetamol. Because all odds ratios associated with paracetamol use without aspirin were greater than unity (although not statistically so), it would appear that paracetamol is possibly associated with gastric ulcer but obviously to a lesser degree than is aspirin. The strong association between paracetamol and gastric ulcer exacerbation ${ }^{58}$ in comparison with the lesser association of this drug with gastric ulcer prior to first symptom may reflect a tendency for patients with dyspepsia to replace aspirin and other NSNSAID's with paracetamol in response to peer

Table 9 Summary of the evidence which indicates that smoking and daily ingestion of analgesic drugs and NSNSAID's are associated with the aetiology of chronic gastric ulcer

\begin{tabular}{|c|c|c|c|}
\hline \multirow{2}{*}{$\begin{array}{l}\text { Criteria } \\
\text { for causal } \\
\text { relationship }\end{array}$} & \multicolumn{3}{|l|}{ Environmental factors } \\
\hline & Smoking & Analgesic drugs & NSNSAID's \\
\hline $\begin{array}{l}\text { Temporal relationship } \\
\text { Strength of association } \\
\text { Consistency of association } \\
\text { Biological gradient } \\
\text { Biological plausibility } \\
\text { Coherence }\end{array}$ & $\begin{array}{l}+ \text { (present study) } \\
+(5, \text { present study }) \\
+(3-5) \\
+(\text { present study }) \\
- \\
\text { No data }\end{array}$ & $\begin{array}{l}+(6, \text { present study }) \\
+(5,8, \text { present study }) \\
+(4-8) \\
+(8, \text { present study }) \\
+(7,24-30) \\
+(24,26)\end{array}$ & $\begin{array}{l}+ \text { (present study) } \\
+ \text { (present study) } \\
+(31) \\
+ \text { (present study) } \\
+(25) \\
+(31)\end{array}$ \\
\hline
\end{tabular}


and medical persuasion.

Aspirin and paracetamol have been shown to produce gastric damage as represented by acute ulcers and microbleeding (reviewed ${ }^{24} 25$ ). Epidemiologically, gastric ulcer is more common in those who frequently ingest aspirin ${ }^{726}$ and probably in those with analgesic related diseases such as rheumatoid arthritis and analgesic nephropathy. ${ }^{24} 26$ Aspirin has been shown to delay the healing of acute ulcers induced in rats. ${ }^{27}$

Both aspirin and paracetamol inhibit the formation of prostaglandins, thereby providing a mechanism for their ulcerogenic action. ${ }^{28}{ }^{29}$ Also, Hansen has shown that the intravenous injection of aspirin and/or paracetamol combined with the infusion of histamine will produce ulceration in cats. ${ }^{30}$

NON-SALICYLATE NON-STEROIDAL ANTI-

INFLAMMATORY DRUGS

These have been studied less but, like aspirin and paracetamol, have been shown to cause microbleeding and acute gastric lesions. ${ }^{25}$ Two series of indomethacin-associated gastric ulcer have been reported. ${ }^{31} 32$ Indomethacin also inhibits the formation of prostaglandins. ${ }^{33}$

As was observed with smoking, the present study reveals a correct temporal relationship between the drug groups studied and the risk of gastric ulcer. The dose response effects observed over a lifetime period with respect to both drug categories indicate the presence of a biological gradient.

The significant associations between risk of gastric ulcer and total amounts consumed of tobacco, of analgesic drugs and of NSNSAID over the lifetime period indicate that the consumption of larger amounts over a shorter period of time is comparable with consumption of smaller amounts over a longer period as regards increased risk of gastric ulcer.

It is noted that, as expected, the strengths of associations found in the three study periods were highly correlated. This finding may reduce the likelihood that response was distorted by recall bias due to time sequences. Such a problem is very real in historical studies which require memory recall over several years. This is especially so where members of a disease group may have a landmark by which to remember activities related to health - for example, analgesic ingestion, whereas healthy control subjects may not. In this study, the allowable symptom history length was limited to five years in an attempt to reduce the problem. Because the associations found were markedly strong, however, a great deal of inaccurate data would be needed to have falsified the significance of the findings.

As regards the validity of interviewing by tele- phone, American studies have shown that the quality of response obtained by telephone interview is highly comparable with that obtained by mail questionnaire $^{16} 17$ and face-to- face interview. ${ }^{16-19}$

The fulfilment in the present study of at least four criteria of causation (Table 9) - correct temporal relationships, strong associations, biological gradients, and consistency with other studies of gastric ulcer as regards strength of associations - suggests that smoking and daily ingestion of analgesic drugs and NSNSAID's may be risk factors for gastric ulcerogenesis. If this is indeed so, the estimated population attributable risks suggest that if these factors were eliminated, the occurrence of gastric ulcer disease would be greatly reduced. Such a reduction would be similar in size to that which would be observed as regards lung cancer incidence if just smoking were eliminated. ${ }^{34}$

This work was supported by the National Health and Medical Research Council of Australia and the Australian Associated Brewers. The help of Lady Eileen Proud and the relatives and friends of the late Sir-Walter Scott is gratefully acknowledged.

\section{References}

1 Grossman MI, Kirsner JB, Gillespie IE. Basal and histalog-stimulated gastric secretion in control subjects and in patients with peptic ulcer or gastric cancer. Gastroterology 1963; 45: 14-26.

2 Baron JH. An assessment of the augmented histamine test in the diagnosis of peptic ulcer. Correlations between gastric secretion, age and sex of patients and site and nature of the ulcer. Gut 1963; 4: 243-53.

3 Doll R, Jones FA, Pygott F. Effect of smoking on the production and maintenance of gastric and duodenal ulcers. Lancet 1958; 1: 657-62.

4 Gillies M, Skyring A. Gastric ulcer, duodenal ulcer and gastric carcinoma: a case control study of certain social and environmental factors. Med J Aust 1968; 2: 1132-6.

5 Piper DW, McIntosh JH, Greig M, Shy CM. Environmental factors and chronic gastric ulcer: a case control study of the association of smoking, alcohol and heavy analgesic ingestion with the exacerbation of chronic gastric ulcer. Scand J Gastroenterol 1982; 17: 721-9.

6 Cameron AJ. Aspirin and gastric ulcer. Mayo Clin Proc 1975; 50: 565-70.

7 Levy M. Aspirin use in patients with major upper gastrointestinal bleeding and peptic ulcer disease. $N$ Engl J Med 1974; 290: 1158-62.

8 Piper DW, McIntosh JH, Ariotti DE, Fenton BH, MacLennan R. Analgesic ingestion and chronic peptic ulcer. Gastroenterology 1981; 80: 427-32.

9 Yerushalmy J, Palmer CE. On the methodology of investigations of etiologic factors in chronic disease. J Chronic Dis 1959; 10: 27-40. 
10 Lilienfeld AM. On the methodology of investigations of etiologic factors in chronic disease. Some comments. J Chronic Dis 1959; 10: 41-6.

11 Hill AB. The environment and disease: association or causation? Proc $R$ Soc Med 1965; 58: 295-300.

12 Evans AS. Causation and disease: a chronological journey. Am J Epidemiol 1978; 108: 249-58.

13 Feinstein AR. Clinical biostatistics XLVII. Scientific standards versus statistical associations and biologic logic in the analysis of causation. Clin Pharmacol Ther 1979; 25: 481-92.

14 Thomas J, Greig M, McIntosh J, Hunt J, McNeil D, Piper DW. The location of chronic gastric ulcer. A study of the relevance of ulcer size, age, sex, alcohol, analgesic intake and smoking. Digestion 1980; 20: 79-84.

15 Congalton AA. Status and prestige in Australia. Melbourne, Sydney: Cheshire Publishing Company, 1969.

16 Hochstim JR. A critical comparison of three strategies of collecting data from households. J Am Stat Assoc 1967; 62: 976-89.

17 Locander W, Sudman S, Bradburn N. An investigation of interview method, threat and response distortion. Proc Am Stat Assoc (Soc Stat Sect) 1974; 21-7.

18 Rogers TF. Interviews by telephone and in person: quality of response and field performance. Pub Opinion $Q$ 1976; 40: 51-65.

19 Simon RJ, Fleiss JL, Fisher B, Gurland BJ. Two methods of psychiatric interviewing: telephone and face-to-face. J Psychol 1974; 88: 141-6.

20 Breslow NE, Day NE. Conditional logistic regression for matched sets. In: Statistical methods in cancer research. Vol 1. The analysis of case control studies. Lyon: International Agency for Research in Cancer, 1980: 248-79.

21 Whittemore AS. Estimating attributable risk from case-control studies. Am J Epidemiol 1983; 117: 76-85.

22 Schesselman JJ. Etiologic fraction in case-control studies, design, conduct, analysis. New York, Oxford: Oxford University Press, 1982.
23 Whitecross DP, Clarke AD, Piper DW, The pepsins of human gastric juice. Scand J Gastroenterol 1974; 9: 399-403.

24 Piper DW, Gellatly R, McIntosh J. Analgesic drugs and peptic ulcer. Human studies. In: Drugs and peptic ulcer. Vol 2. Florida, USA: CRC Press, 1982: 75-93.

25 Prescott LF. Antipyretic analgesics. In: Dukes MNG, ed. Meyler's side-effects of drugs. Amsterdam: Excerpta Medica, 1976: 64-85.

26 Silvoso GR, Ivey KJ, Butt JH et al. Incidence of gastric lesions in patients with rheumatic disease on chronic aspirin therapy. Ann Intern Med 1979; 91: 517-20.

27 Szelenyi I, Engler H, Herzog P, Postius S, Vergin H, Holtermüller $\mathrm{KH}$. Influence of non-steroidal antiinflammatory compounds on healing of chronic gastric ulcers in rats. Agents Actions 1982; 12: 180-2.

28 Konturek SJ, Obtulowicz W, Sito E, Oleksy J, Wilkon $\mathrm{S}$, Kiec-dembinska A. Distribution of prostaglandins in gastric and duodenal mucosa of healthy subjects and duodenal ulcer patients: effects of aspirin and paracetamol. Gut 1981; 22: 283-9.

29 McDonald-Gibson WJ, Collier HO. Paracetamol potentiates acetylsalicylate in inhibiting prostaglandin synthesis. Eur J Pharmacol 1979; 58: 497-500.

30 Hansen DG, Aures D, Grossman MI. Histamine augments gastric ulceration produced by intravenous aspirin in cats. Gastroenterology 1978; 74: 540-3.

31 Taylor RT, Huskisson EC, Whitehouse GH, Hart FD, Trapnell DH. Gastric ulceration occurring during indomethacin therapy. $\mathrm{Br} \mathrm{Med} J$ 1968; 4: 734-7.

32 Maclaurin BP, Richards DA, Heads D. Indomethacinassociated peptic ulceration. NZ Med J 1978; 88: 439-41.

33 Uotila P, Männistö J, Simberg N, Hartiala K. Indomethacin inhibits arachidonic and metabolism via lipoxygenase and cyclo-oxygenase in hamster isolated lungs. Prostaglandins Med 1981; 7: 591-9.

34 Lilienfeld AM, Lilienfeld DE. In: Foundations of epidemiology, 2nd ed. New York: Oxford University Press, 1980: 218. 